Case Report

\title{
The Two Huge Pulmonary Hydatid Cyst in the One Lobe of Lung: A Case Report
}

\section{Gökhan ÖZTÜRK ${ }^{1}$}

${ }^{1}$ Pamukkale University Faculty of Medicine, Department of Chest Surgery, Denizli, Turkey

\begin{abstract}
The hydatid cysts disease is a parasitic cystic infection of the liver, lungs, and other organs caused by Echinococcus granulosus. It is mostly seen in the sheep and cattle farms, which have poor health conditions. It is endemic in the eastern and southwestern regions of Turkey. The big cysts seen in the lungs are called huge pulmonary cysts, and it is a particular clinical situation. The symptoms of the disease are cough, chest pain, dyspnoea, hemoptysis, or allergic reactions. The hemoptysis could be seen when these cysts rupture. The use of anthelmintic drugs to treat the pulmonary hydatid cysts could cause cyst rupture. The surgery must be the first choice of treatment. I reported two large pulmonary hydatid cysts in the left upper lobe of the lung that I treated with thoracotomy.
\end{abstract}

Turk J Int Med 2021;3(Supplement 1):S113-S116 DOI: $10.46310 /$ tjim. 876357

Keywords: The hydatid cysts, thoracotomy, cystotomy, quilting

\section{Introduction}

The hydatid disease (Echinococcosus) is a common parasitic infection in agricultural communities, especially in the middle east and Mediterranean countries and the sheep and cattle farms. ${ }^{1}$ It is endemic in the eastern and southwestern regions of Turkey. ${ }^{1,2}$ Echinococcus granulosus mostly involves the liver and lungs. It is mainly seen in the liver (60-70\%) and the lungs (20-30\%). The extrapulmonary involvement in the thoracic cavity is infrequent. ${ }^{3}$ The recurrence rate of hydatid cyst after surgery is $1.4 \%$ in the lung and $11.3 \%$ in the liver. The cyst's growth rate varies depending on the host's immunity and the elasticity of the organ in which it is located., While tissue resistance and hepatobiliary capsules in the liver limit the cyst's growth, the lung tissue's low tissue resistance is favorable for the rapid growth of hydatid cysts. ${ }^{5}$ The immune response against the parasite and the symptoms caused by the patient's mass effect prevent the cyst's limitless growth. The disease is usually diagnosed in a patient living in an endemic area by radiological

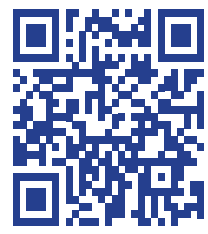




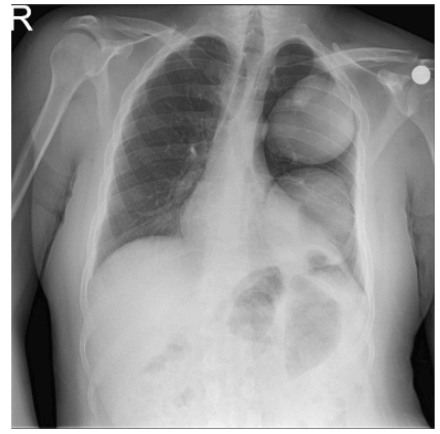

Figure 1. Preoperative posterioranterior chest radiography

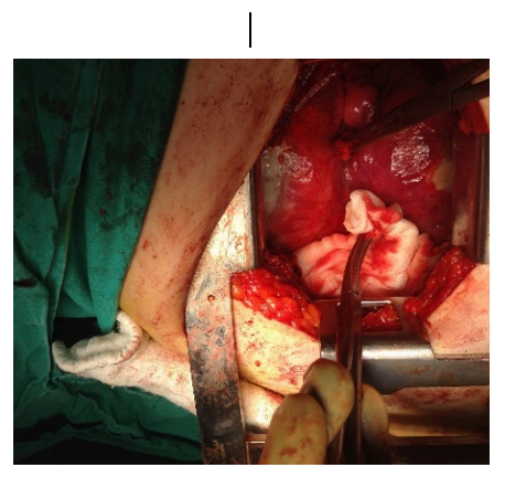

Figure 4. Photograph of cystic lesions in the left upper lobe after thoracotomy (superior cystic lesion on the left, inferior cystic lesion on the right)

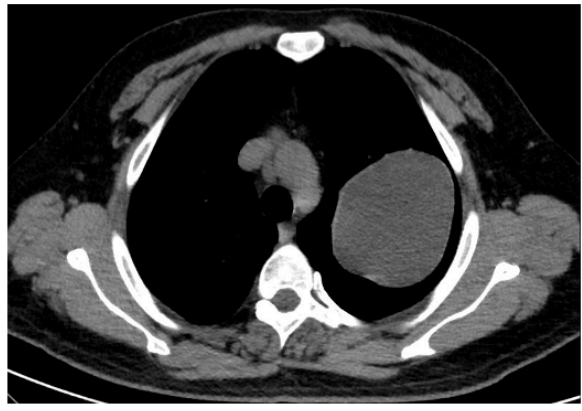

Figure 2. The thoracic CT image of the cyst in the left superior lobe

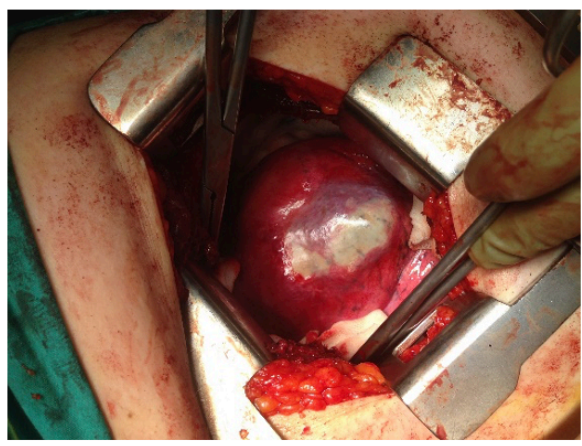

Figure 5. Photograph of the inferior cystic lesion after thoracotomy

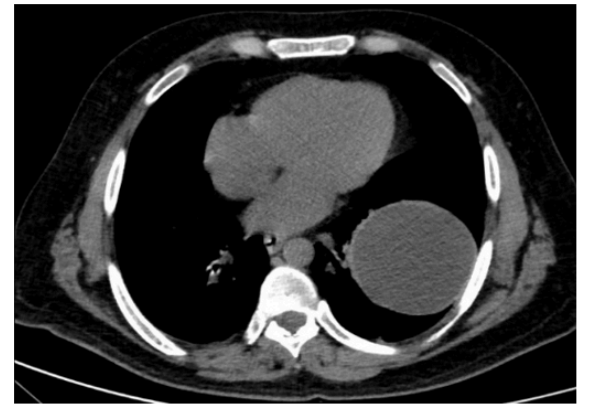

Figure 3. The thoracic CT image of the cyst in the left inferior lobe

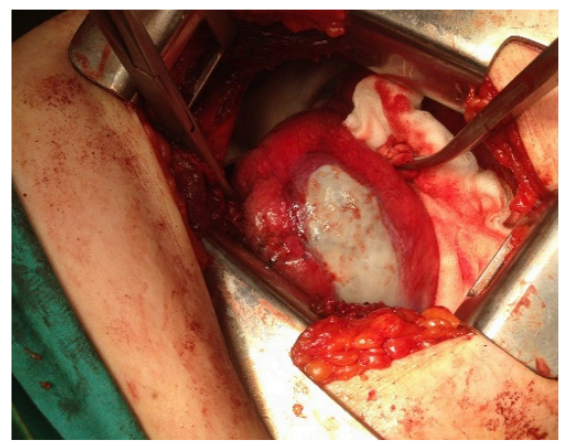

Figure 6. Photograph of superior cystic lesion after thoracotomy examinations or radiological examinations taken for other reasons. ${ }^{6,7}$ Cough, chest pain, dyspnea, hemoptysis, or allergic reactions may occur in symptomatic patients. Cysts rarely reach six centimeters in diameter. ${ }^{8}$ Large cysts in the lungs are called giant pulmonary cysts. In our case, two cysts of $8 \mathrm{~cm}$ and $10 \mathrm{~cm}$ in diameter were accepted as giant pulmonary hydatid cysts. In this case, I discussed two large pulmonary hydatid cysts in the left upper lobe of the lung treated by thoracotomy.

\section{Case Report}

A 38-year-old mentally disabled male patient was admitted to the hospital with a hacking cough for three months. He was diagnosed with a left lung hydatid cyst by posterior-anterior chest radiography (PALG) (Figure 1). He had no comorbid disease or medication. In thoracic computed tomography imaging (CTI), there was a cyst involving approximately $10 \times 7 \mathrm{~cm}$ of the left lobe of the lung, and another cyst of $8 \times 8 \mathrm{~cm}$ inferior to this cyst (Figures 2 and 3). On his exploration, two lesions compatible with hydatid cysts in the left upper lobe of the lung, and total atelectasis in the lower lobe were observed (Figures 4-6). I entered the inferior cyst with the needle connected to the aspiration apparatus, and 500 $\mathrm{mL}$ of rock water was aspirated (Figure 7). The pericystic layer was cut with electrocautery. After the cystotomy, the germinative membrane was removed (Figure 8). Later, the same procedure was applied to the upper lesion. $600 \mathrm{~mL}$ of rock water was aspirated. Bronchial fistulas in both cystic cavities were closed with $3 / 0$ prolene and quilted with 3/0 vicryl (Figures 9 and 10). When the left lung was ventilated, the upper lobe and atelectasis lower lobe were ventilated. A thoracic drain was inserted, and the patient was closed, and the lungs were expanded in the control PALG radiography (Figure 11). He was discharged on the 4th day. Pathology examinations confirmed the diagnosis 


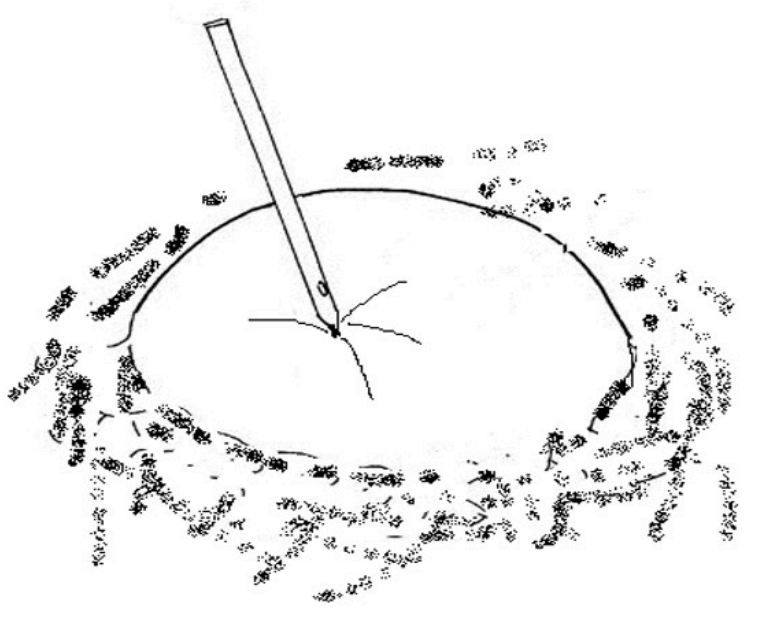

Figure 7. Intra-cyst rock water aspiration

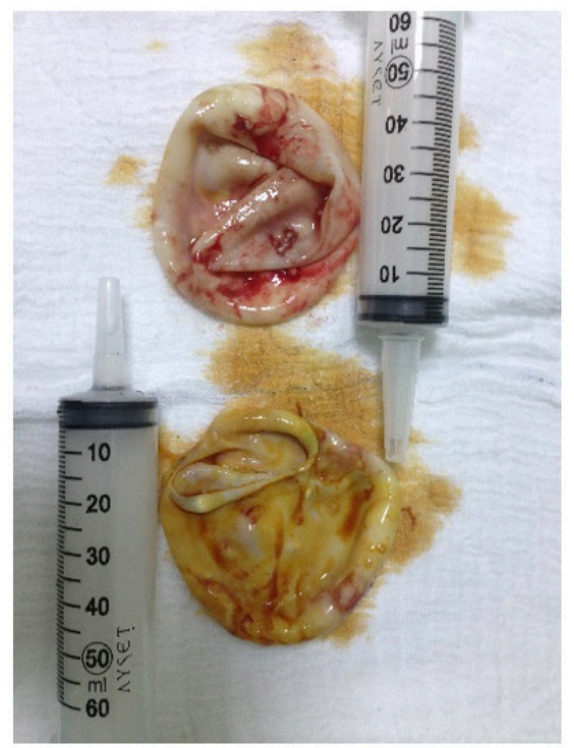

Figure 8. Germinative membrane of a hydatid cyst. He received albendazole treatment to preventing relapse. There was no recurrence in his 6-month follow-up.

\section{Discussion}

PALG and thoracic CT are usually sufficient for the diagnosis of pulmonary hydatid cysts. ${ }^{9-11}$ Pathological confirmation is required for the definitive diagnosis. Patients with hydatid cysts are usually asymptomatic. Symptomatic patients present with cough, chest pain, shortness of breath, hemoptysis, or allergic reactions. Cystic fluid, germinative membrane expectoration, and infection may be observed in ruptured cysts.
The parasite's growth rate depends on the host's immune response and the tissue's properties in which the cyst is located. Its' large size can change the clinic, treatment, and postoperative course of pulmonary hydatid disease. In this disease, it is rare for the cyst to reach $6 \mathrm{~cm}$ in diameter. In our study, two cysts in one lobe with $10 \mathrm{~cm}$ and $8 \mathrm{~cm}$ diameter were accepted as giant hydatid lung cysts. In the treatment of pulmonary hydatid cyst, parenchyma sparing operations are preferred more frequently., ${ }^{9,12}$ Lung resection should be avoided because the compressed lung parenchyma is generally healthy and expands in the postoperative period. Cystotomy and quilting procedure was applied to our patient. Treatment

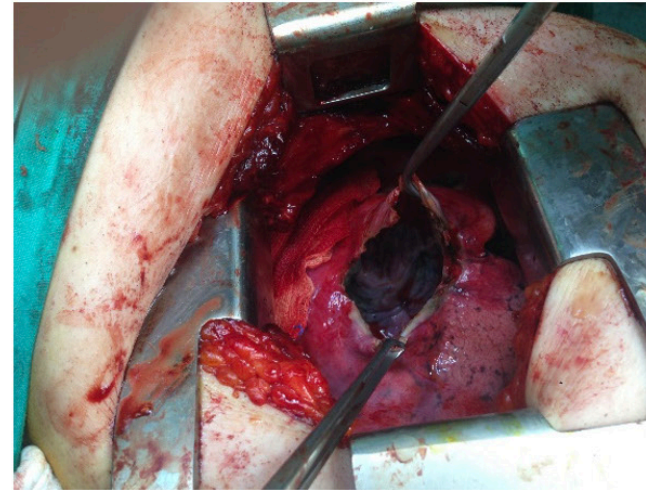

Figure 9. Photograph of the inferior cystic lesion after cystotomy and cystic membrane removal

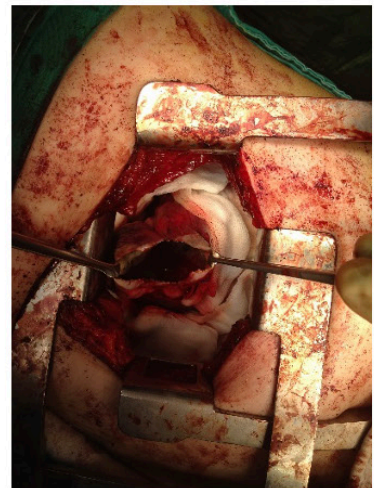

Figure 10. Photograph of superior cystic lesion after cystotomy and cystic

membrane removal

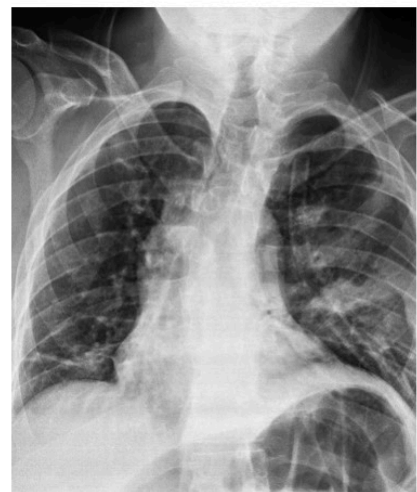

Figure 11. Post-operative PALG 
with anthelmintics can cause cyst rupture. We recommend this treatment only in patients who cannot tolerate surgery and to prevent a recurrence.

\section{Conflict of Interests}

Authors declare that there are none.

\section{Acknowledgment}

This study has been presented in $17^{\text {th }}$ Uludag Internal Medicine National Winter Congress, $6^{\text {th }}$ Bursa Family Medicine Association National Congress, $11^{\text {th }}$ Uludag Internal Medicine Nursing Congress, 5-7 March 2021, Bursa, Turkey.

\section{References}

1. Topcu S, Kurul IC, Altinok T, Yazici U, Demir A. Giant hydatid cysts of lung and liver. Ann Thorac Surg. 2003 Jan;75(1):292-4. doi: 10.1016/s0003-4975(02)03701-3.

2. Yekeler E, Celik O, Becerik C. A giant ruptured hydatid cyst causing tension pneumothorax and hemothorax in a patient with blunt thoracic trauma: a rare case encountered in the emergency clinic. J Emerg Med. 2012 Jul;43(1):111-3. doi: 10.1016/j.jemermed.2009.04.066.

3. Sehgal S, Mishra B, Thakur A, Dogra V, Loomba PS, Banerjee A. Hydatid cyst of mediastinum. Indian J Med Microbiol. 2008 Jan-Mar;26(1):80-1. doi: 10.4103/02550857.38867.

4. Bakir F. Serious complications of hydatid cyst of the lung. Am Rev Respir Dis. 1967 Sep;96(3):483-93. doi: 10.1164/arrd.1967.96.3.483.
5. Guntz M, Coppo B, Lorimier G, Cornier P. Les kystes hydatiques du foie de revelation tardive (10 a 22 ans) apres traitment chirurgical d'une hydatidose pulmonaire. Problemes physiopathologiques. J Chir Paris. 1990;127:375-81 (in French).

6. Ramos G, Duque JL, Yuste MG, Heras F, Gallo MJ, Beltran de Heredia M. La rupture intrapleurale du kyste hydatique du poumon. Apropos dequinze observations. Ann Chir: Chir Thorac Cardiovasc 1983;7:114-6.

7. Karaoglanoglu N, Gorguner M, Eroglu A. Hydatid disease of rib. Ann Thorac Surg. 2001 Jan;71(1):372-3. doi: 10.1016/s0003-4975(00)02010-5.

8. Lamy AL, Cameron BH, LeBlanc JG, Culham JA, Blair GK, Taylor GP. Giant hydatid lung cysts in the Canadian northwest: outcome of conservative treatment in three children. J Pediatr Surg. 1993 Sep;28(9):1140-3. doi: 10.1016/0022-3468(93)90149-f.

9. Halezeroglu S, Celik M, Uysal A, Senol C, Keles M, Arman B. Giant hydatid cysts of the lung. J Thorac Cardiovasc Surg. 1997 Apr;113(4):712-7. doi: 10.1016/ S0022-5223(97)70228-9.

10. Qian ZX. Thoracic hydatid cysts: a report of 842 cases treated over a thirty-year period. Ann Thorac Surg. 1988 Sep;46(3):342-6. doi: 10.1016/s0003-4975(10)65941-3.

11. Aletras H, Symbas PN. Hydatid disease of the lung. In: Shields TW, LoCicero III J, Ponn RB, eds. General Thoracic Surgery. Philadelphia, PA: Lippincott Williams and Wilkins; 2000:1113-22.

12. Do $\square$ an R, Yüksel M, Cetin G, Süzer K, Alp M, Kaya S, Unlü M, Moldibi B. Surgical treatment of hydatid cysts of the lung: report on 1055 patients. Thorax. 1989 Mar;44(3):192-9. doi: 10.1136/thx.44.3.192.

13. Burgos L, Baquerizo A, Muñoz W, de Aretxabala $X$, Solar C, Fonseca L. Experience in the surgical treatment of 331 patients with pulmonary hydatidosis. J Thorac Cardiovasc Surg. 1991 Sep;102(3):427-30. 